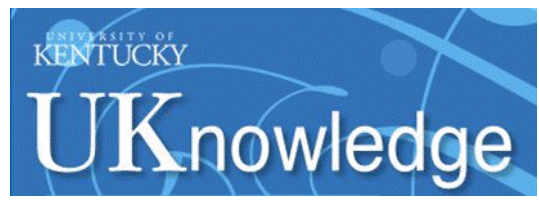

University of Kentucky

UKnowledge

\title{
On the Optimal Energy Controls for Large Scale Residential Communities Including Smart Homes
}

\author{
Huangjie Gong \\ University of Kentucky, huangjie.gong@uky.edu \\ Vandana Rallabandi \\ University of Kentucky, vandana.rallabandi@uky.edu \\ Michael L. Mclntyre \\ University of Louisville \\ Dan M. Ionel \\ University of Kentucky, dan.ionel@uky.edu
}

Follow this and additional works at: https://uknowledge.uky.edu/peik_facpub

Part of the Power and Energy Commons

Right click to open a feedback form in a new tab to let us know how this document benefits you.

\section{Repository Citation}

Gong, Huangjie; Rallabandi, Vandana; McIntyre, Michael L.; and Ionel, Dan M., "On the Optimal Energy Controls for Large Scale Residential Communities Including Smart Homes" (2019). Power and Energy Institute of Kentucky Faculty Publications. 13.

https://uknowledge.uky.edu/peik_facpub/13

This Conference Proceeding is brought to you for free and open access by the Power and Energy Institute of Kentucky at UKnowledge. It has been accepted for inclusion in Power and Energy Institute of Kentucky Faculty Publications by an authorized administrator of UKnowledge. For more information, please contact UKnowledge@lsv.uky.edu. 


\title{
On the Optimal Energy Controls for Large Scale Residential Communities Including Smart Homes
}

\author{
Digital Object Identifier (DOI) \\ https://doi.org/10.1109/ECCE.2019.8912490
}

\section{Notes/Citation Information}

Published in 2019 IEEE Energy Conversion Congress and Exposition (ECCE).

(C) 2019 IEEE Copyright Notice. "Personal use of this material is permitted. Permission from IEEE must be obtained for all other uses, in any current or future media, including reprinting/republishing this material for advertising or promotional purposes, creating new collective works, for resale or redistribution to servers or lists, or reuse of any copyrighted component of this work in other works."

The document available for download is the authors' manuscript version that is accepted for publication. The final published version is copyrighted by IEEE and available as: H. Gong, V. Rallabandi, M. L. Mclntyre, and D. M.Ionel, "On the Optimal Energy Controls for Large Scale Residential Communities including Smart Homes," Rec. 2019 IEEE Energy Conversion Congress and Exposition (ECCE), Baltimore, MD, Sept 2019, pp. 503-507, doi: 10.1109/ECCE.2019.891249 


\title{
On the Optimal Energy Controls for Large Scale Residential Communities including Smart Homes
}

\author{
Huangjie Gong ${ }^{1}$, Vandana Rallabandi ${ }^{* 1}$, Michael L McIntyre ${ }^{2}$, and Dan M. Ionel ${ }^{1}$ \\ ${ }^{1}$ SPARK Lab, ECE Department, University of Kentucky, Lexington, KY, USA \\ huangjie.gong@uky.edu, vandana.rallabandi@ieee.org, dan.ionel@ieee.org \\ ${ }^{2}$ ECE Department, University of Louisville, Louisville, KY, USA \\ michael.mcintyre@louisville.edu
}

\begin{abstract}
Residences with smart home energy management (HEM) systems and solar generation are modifying domestic load profiles. Moreover, the growing penetration of solar photovoltaic (PV) energy brings the total net power demand further down as houses become local generators. High PV penetration introduces technical challenges for the power system including the "duck curve". This paper proposes a co-simulation framework for high PV penetration smart energy communities which allows the simultaneous simulation of home energy consumption along with control algorithms for each house, as well as system power flow. Models are developed and presented for one of the largest rural field demonstrators for smart energy technologies comprising industrial, business, and 5,000+ residences, located in Glasgow, KY, US. The objectives of the HEM system are to reduce the total energy consumption and peak demand by controlling the heating ventilation and air-conditioning (HVAC) systems, water heaters, and batteries, so as to benefit both consumers and the utility. The advantages to the residential consumers include reduced electricity bills and the utility benefits from lower peak demand. Case studies are conducted for typical winter and summer days and simulation and experimental results are presented. The paper also includes long term load prediction for the utility considering different percentages of smart homes.
\end{abstract}

Index Terms-Smart Home, Home Energy Management (HEM), Battery Energy Storage System (BESS), Home Energy Model, Power System.

\section{INTRODUCTION}

Futuristic smart homes integrate information technology to increase energy efficiency, allow owners to manage electricity usage, improve reliability and stability, and enable the use of innovative technologies including solar photovoltaic (PV), energy storage, and other smart devices [1]. The smart home concept plays a key role in the development of strategies toward a sustainable future, as it not only facilitates the integration of renewable energy and high efficiency residential appliances, but also encourages the participation of everyone in power generation [2].

Smart homes, which can be considered as distributed generators, are changing operation of utilities by reducing the residential energy consumption and lowering the peak demand. Smart homes reduce energy consumption by improved

\footnotetext{
* Dr. Vandana Rallabandi was with the SPARK Laboratory, ECE Department, University of Kentucky, Lexington, KY and is now with GE Research, Niskayuna, NY.
}

building insulation, which reduces heating ventilation and air-conditioning (HVAC) demand and by utilizing intelligent control systems to turn off idle devices. Other characteristics of smart homes include the ability to control the appliances in coordination with commands from the utility. With the increasing penetration of solar PV, smart homes in a power system become prosumers, providing electricity from their own renewable resources when there is surplus generation and buying power at other times.

In the futuristic residential community, high penetration of PV introduces technical challenges for the power system such as the "duck curve", which occurs when the net power demand changes from very low to high values within a few hours, typically, from the afternoon to the evening [3]. Utility plants are required to maintain the "minimum generation" needed for local voltage support and reliability issues arise even when power generation is reduced to accommodate the high PV generation in the middle of the day [4]. In the evening, expensive generators are required to cope with the fast increasing power demand when PV is not available [5].

To mitigate the "duck curve" while harvesting the maximum solar energy, the home energy management (HEM) systems for net zero energy (NZE) homes aim at not only reducing the peak demand, but also self-consuming the maximum local PV generation. In this regard, a home is utilized as virtual energy storage due to its thermal inertia [6]. This is achieved by using the thermal components including the HVAC system and the electric water heater $(\mathrm{EWH})$ for preheating and precooling in order to avoid the evening peak demand.

This paper studies the Smart Energy Technologies (SET) project from Glasgow, KY, a city for which utility services are provided by the municipal Electric Plant Board (EPB) in partnership with the Tennessee Valley Authority (TVA) [7]. This SET project is currently one of the largest advanced high efficiency community field demonstrators in rural US. The proposed software platform is employed to model the entire community including residential, industrial, and business sectors. The model includes a HEM system, realized by controlling the HVAC, EWH and residential BESS to reduce peak demand and energy consumption. The results from the model are validated against measurements. 


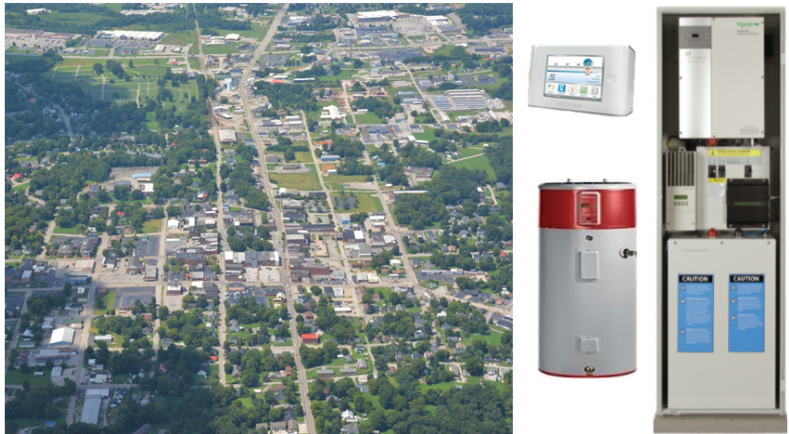

Fig. 1. Aerial view of Glasgow, KY, the location of the studied SET, along with pictures of smart devices for home energy management: thermostat, EWH and BESS, which are programmable and enabled by WiFi or Ethernet The data acquired has a resolution of up to 1 minute and is available for both home owners and the utility.

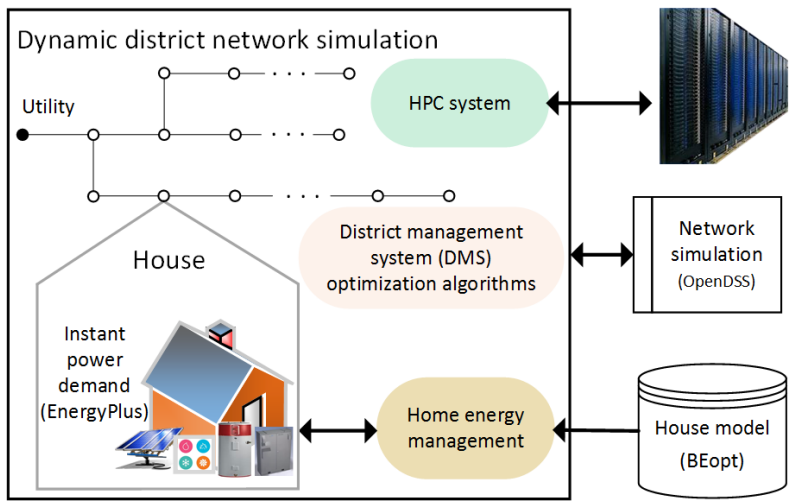

Fig. 2. Schematic representation of the INSPIRE+D proposed simulation software framework, solely based on freeware, capable of running thousands of house energy models in parallel and concurrently performing power flow optimization.

The total load profile for the utility in the long term is calculated considering the trends for increasing percentages of smart homes and the PV penetration in the residential community.

\section{BACKGROUND INFORMATION}

The homes participating in the studied SET project employ building upgrades and highly efficient and controllable devices. Currently, more than 300 homes out of the total 5,000+ residences from Glasgow, KY, are participating in the project, leading to approximately $600,000 \mathrm{kWh}$ of energy saving every year (Fig. 1).

Enabled by smart devices, bi-directional communications and integrated management, homes in the SET project function as controllable loads that interact with the grid in a dynamic way, facilitating coordination so as to achieve peak demand reduction, load shifting and energy saving. A SET home receives energy efficiency improvements to their homes such as better insulation, and more efficient HVAC systems. These features make the energy consumption of some of the SET homes lower than that of the average residences though they are all single-family houses with relatively larger area. Moreover,

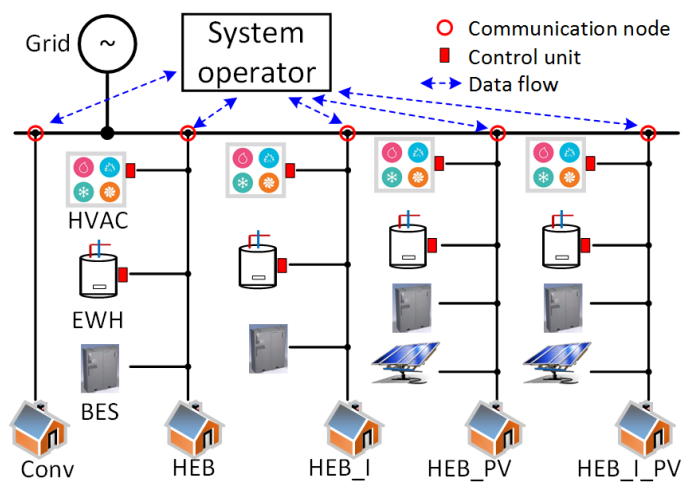

Fig. 3. The proposed system model includes five types of SET homes, each type being representative of thousands of individual houses. In the study, the load data for the business and industrial sectors is provided by experimental measurements.

programmable WiFi-enabled thermostats, heat-pump EWH, and a residential BESS allow the SET homes to perform realtime HEM.

In this paper, the data of aggregated residential net power flow is provided by the utility and serves as the baseline case. The baseline case presents typical power demand for the distribution system where most of the residences are conventional houses without PV. The solar PV system for each house is sized for each house to meet the NZE mandate and the generation is simulated and added to the net power consumption of the houses.

The simulation for the power system formed by the SET community including over 5,000 homes is realized by an innovative, first of its kind, software framework 'Integrated Network simulation for Smart Power-flow In Residences using EnergyPlus and OpenDSS' (INSPIRE+D) (Fig. 2). INSPIRE+D incorporates freeware such as BEopt, EnergyPlus, OpenDSS, and Python, and is capable of both power flow analysis at the system level, as well as house energy modeling along with HEM at the single house level. Its scalability enables the simulation of thousands of different house models in parallel, using a high performance computing (HPC) system with thousands of cores.

\section{Energy Consumption Models And Home ENERGY MANAGEMENT}

The electric power demand of the Glasgow EPB service comprises industrial, business and residential sectors. The presented system modeling focuses on the residential sector and the aggregated effects of controlling single SET homes (Fig. 3). The community includes five types of houses: conventional residences without any smart devices and four types of SET homes, which are: residences with HVAC, EWH and BESS control (HEB), the HEB house with improved Insulation (HEB_I), and the HEB, HEB_I house with local solar PV panels (HEB_PV, HEB_I_PV) (Fig. 3).

The net load for a residence with HEM_I_PV is decided by the combined power of HVAC, EWH, other loads, BESS, 


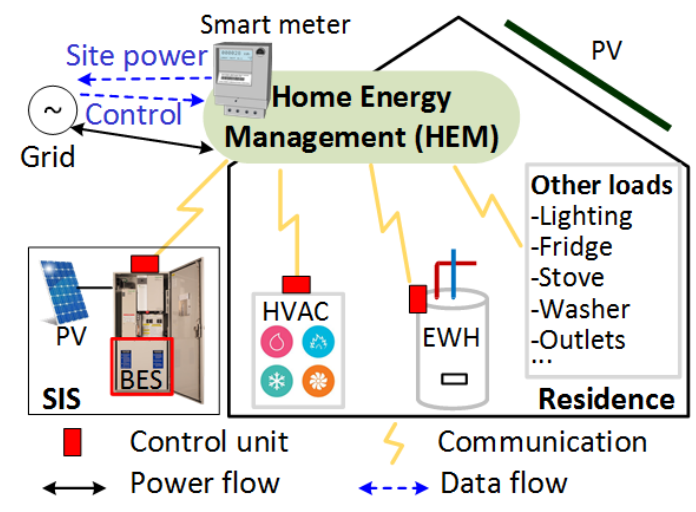

Fig. 4. The proposed home energy management scheme for the SET homes. Solar PV and BESS are integrated into a Solar Integration System (SIS). HVAC and EWH load demands are controlled through temperature set points.

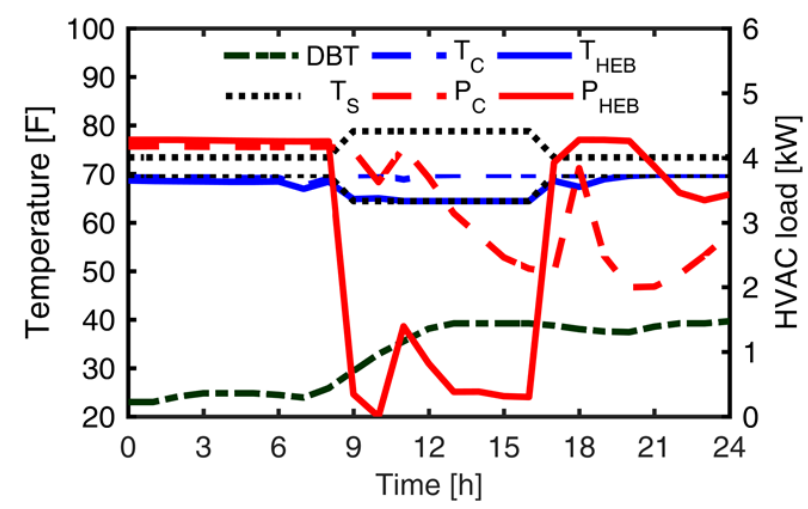

Fig. 5. Simulated HVAC power demand for a typical home on 1/19/2017. A house of the conventional type (denoted by a suffix ' $C$ ') without HVAC control has higher HVAC power in the afternoon. In a HEB-type home, the capability of changing the heating set point $\left(T_{S}\right)$, leads to lower HVAC power in the afternoon when the owner is away.

and PV (Fig. 4). The net load for a HEM house at time $t$ is calculated as

$$
P_{H}^{t}=P_{H V A C}^{t}+P_{E}^{t}+P_{O}^{t}+P_{B}^{t}-P_{P V}^{t}
$$

where $P_{H}$ is the residential net power flow; $P_{H V A C}, P_{E}$, $P_{O}, P_{B}$ and $P_{P V}$ are the powers of the HVAC system, the EWH, other loads, the BESS and PV, respectively. It may be noted that for the BESS, positive and negative powers indicate charging and discharging, respectively.

The HVAC power is represented as a function of the thermostat set point temperature change by the following,

$$
P_{H V A C}^{t}=f\left(\Delta T_{R}^{t}\right) .
$$

Consumer comfort is taken into account by limiting the heating and cooling set points:

$$
T_{H}^{t} \leq T_{R}^{t-1}+\Delta T_{R}^{t} \leq T_{C}^{t},
$$

where $T_{R}, T_{H}$, and $T_{C}$ stand for the room temperature, set points for heating and cooling, respectively.

Previous research works show that the room temperature is

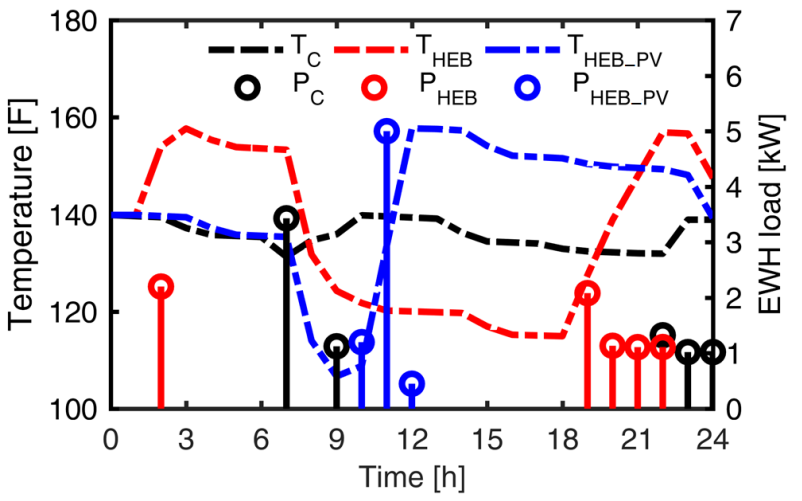

Fig. 6. Water temperature in the tank and instantaneous power of EWH. HEB homes shift the EWH load to the morning and the evening. When equipped with solar PV, SET homes shift the EWH load to the afternoon to absorb surplus PV generation.

influenced by factors including outdoor and ground temperatures, floor space, human activities and the heat radiation from indoor appliances [8].

The water tank temperature is limited as follows,

$$
T_{S}^{t}-\Delta T_{D} \leq T_{E}^{t} \leq T_{S}^{t},
$$

where $T_{S}$ is the set point of the EWH; $\Delta T_{D}$, the dead band of the $\mathrm{EWH}$, which is set to $20^{\circ} \mathrm{C}, T_{E}^{t}$ the temperature of water in the EWH tank. $T_{E}^{t}$ is updated automatically by the house energy model. The water heater power is decided by the nominal power and its status from the following,

$$
P_{E}^{t}=P_{E, N} \cdot S_{E}^{t},
$$

where $P_{E, N}$ is the nominal power of the EWH. The status of $\mathrm{EWH}, S_{E}^{t}$, is decided by the water temperature in the tank, set points and the dead band as per the following,

$$
S_{E}^{t}= \begin{cases}0=O F F, & T_{E}^{t}>T_{S}^{t}, \\ 1=O N, & T_{E}^{t}<T_{S}^{t}-\Delta T_{D}, \\ S_{E}^{t-1}, & \text { other. }\end{cases}
$$

The power of the EWH is collectively decided by (4) - (6). EWH is controlled ON and OFF by adjusting the input of $T_{S}^{t}$.

The net power flow of the NZE house is defined as a function of the controllable loads, in this case, the BESS and the EWH, and well as the HVAC as below,

$$
P_{H}^{t}=f\left(P_{B}^{t}, T_{S}^{t}, T_{H}^{t}, T_{C}^{t}\right) .
$$

EnergyPlus software is used to build the house energy model and test the impacts brought about by the HVAC and EWH control. It may be noted that the user can over-ride the HEM controls if desired. The SET homes with the HEM system have lower HVAC load on both the studied summer and winter days due to the improved insulation. The HVAC performance of an example SET home and a conventional house are compared for the studied winter day when the dry bulb temperature (DBT) is low (Fig. 5). In the afternoon when the SET house owner is away, the thermostat setting point $\left(T_{S}\right)$ is set low in order 


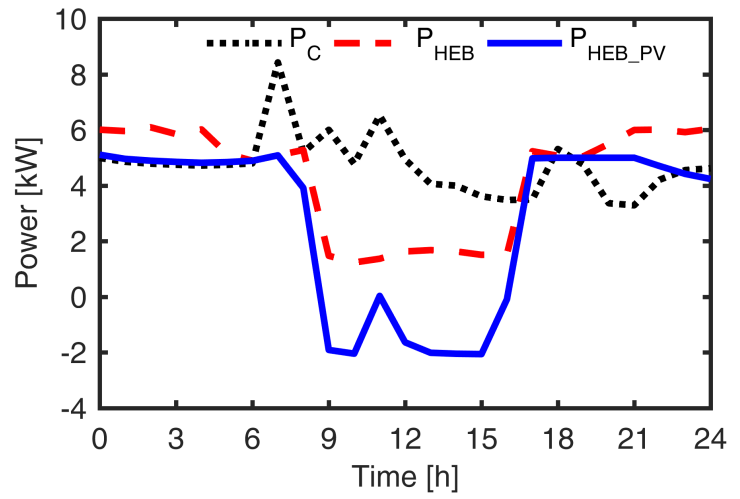

Fig. 7. Simulated net power demand for a single-family house. The demands for HEB and HEB+PV houses are shaped by controlling the HVAC, EWH and BESS.

to reduce the HVAC load. $T_{S}$ is changed back at 17:00 before the house owner returns home.

The EWH control is realized by changing the set point which triggers the heating process. The high specific heat capacity of water, mixing valves and negligible heat loss enable advanced controls, for e.g. postponed electric heating load while maintaining consumer comfort [9]. Three EWH working schemes and their corresponding tank temperatures are shown (Fig. 6). Without any control, peak power due to EWH operation occurs in the morning. In a HEB-type house without solar PV generation, the EWH operates in the early morning and at midnight to avoid the morning peak. In the residences with $\mathrm{PV}$, the EWH load is shifted to the afternoon to absorb excess PV generation.

The BESS control adds increased flexibility to the HEM system, as charge and discharge operations do not influence consumer comfort. In the proposed HEM control, the BESS is operated to smooth the residential power demand as well as to further reduce the peak (Fig. 7).

\section{CAse Studies}

Case studies for the community with different penetration of technologies, i.e. house types, are defined in Table. I. The baseline case (BL) is provided by experimental data and stands for the current field situation where only $300+$ out of $5,000+$ residences are SET homes, and none of them has a PV installation. The second case does not incorporate HEM control and validates the model as the aggregated net power flow has a similar curve to the baseline case. The lower total energy consumption of case 2 is due to the increased efficiency of the HEM_I homes with improved insulation. Cases 2 to 5 present the gradual shift to a futuristic high energy efficiency and distributed PV generation community. The distribution power system for each case study was simulated based on a modified IEEE 13-node test case and solved by OpenDSS.

Two representative days from the year 2017 were chosen for the case studies. On the studied winter day of 1/19/2017 in Glasgow, KY, the aggregated residential power demand peaks in the morning and evening as shown in the "Baseline" curve
Table I

CASE STUDIES WITH DIFFERENT PERCENTAGE DISTRIBUTIONS OF HOUSE TYPES IN THE COMMUNITY POWER SYSTEM

\begin{tabular}{cccccc}
\hline Cases & $\begin{array}{c}\text { Conv } \\
(\%)\end{array}$ & $\begin{array}{c}\text { HEB } \\
(\%)\end{array}$ & $\begin{array}{c}\text { HEB_I } \\
(\%)\end{array}$ & $\begin{array}{c}\text { HEB_PV } \\
(\%)\end{array}$ & $\begin{array}{c}\text { HEB_I_PV } \\
(\%)\end{array}$ \\
\hline BL & $>94$ & $<3$ & $<3$ & 0 & 0 \\
2 & 50 & 25 & 25 & 0 & 0 \\
3 & 50 & 0 & 0 & 25 & 25 \\
4 & 20 & 20 & 20 & 20 & 20 \\
5 & 0 & 25 & 25 & 25 & 25 \\
\hline
\end{tabular}

(Fig. 8 (a)). On this winter day, the residential load drops in the afternoon because of the solar irradiance, which brings heat into the room through walls and windows. With high PV penetration, the aggregated net power flow decreases further in the afternoon, creating a significant "duck curve" profile (Fig. 8 (a)).

The HEB_I type homes with imporved insulation contribute to residential load reduction, it may be seen that even when as few as $25 \%$ of the houses are of the HEB_I type, the power consumption reduces substantially (Fig. 8 (a)). Similar observations can also be made for the studied summer day of 7/20/2017 (Fig. 8 (b)).

With the proposed HEM control, the SET houses behave like thermal and electrical energy storage systems, thereby reducing the peaks in the morning and evening in both cases (Fig. 9 (a)). Case 2, which features HEB_I homes has lower energy consumption than baseline even though there is no PV generation. The $50 \%$ penetration of SET homes in case 2 allows the power system to shift the peaks and reduce the ramp rates due to the combined operation of the controllable EWH and HVAC loads, and the BESS.

Case 3 presents the "duck curve" because the energy storage capacity provided by controllable loads and BESS with $50 \%$ penetration of SET homes is not sufficient to absorb all the surplus PV generation and supply the total evening power demand. The "duck curve" is mitigated to a certain degree in case 4, due to the combined effects of larger percentage of SET homes and reduced solar penetrations.

Case 5 has the same PV generation as case 3, but with $100 \%$ of SET homes in the power system. It may be observed that case 5 features the lowest power consumption, peak demand and peak to peak value. Similar observations are also applicable to the studied summer's day of 7/20/2017 (Fig. 9 (b)). These results indicate that high PV penetration would not constitute a challenge for the utility grid, if appropriate HEM systems are in place.

\section{CONCLUSION}

This paper employs a newly developed, first of its kind, innovative co-simulation framework to analyze one of largest field demonstrators in rural US area for smart energy technologies. The Glasgow, KY, community studied includes over 5,000 homes, with more than 300 smart homes, as well as 


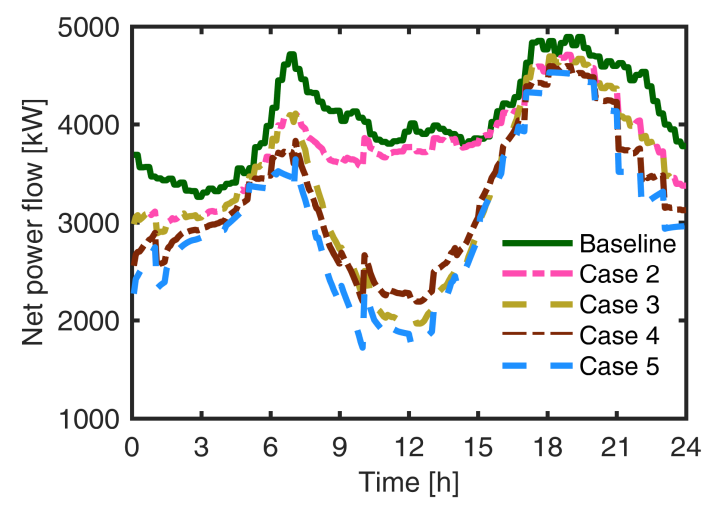

(a)

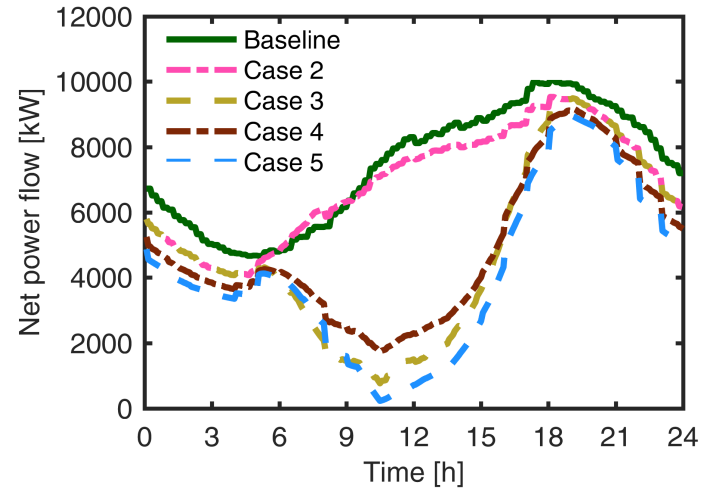

(b)

Fig. 8. Aggregated residential net power flow without HEM for the studied winter (a) and summer (b) day, respectively. A high penetration of solar PV exacerbates the "duck curve".

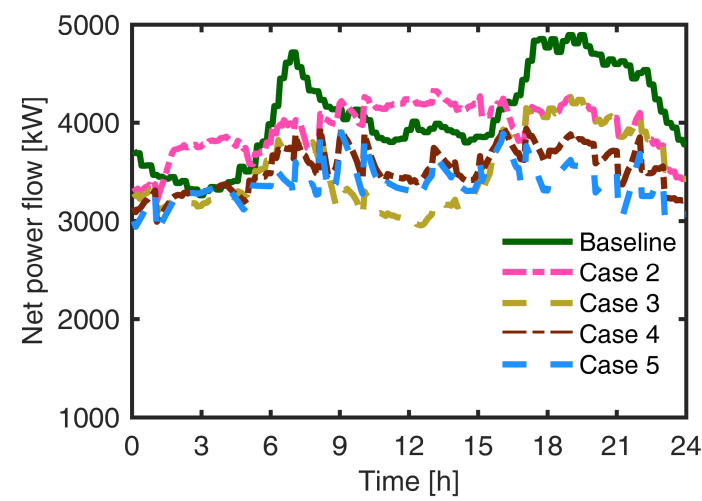

(a)

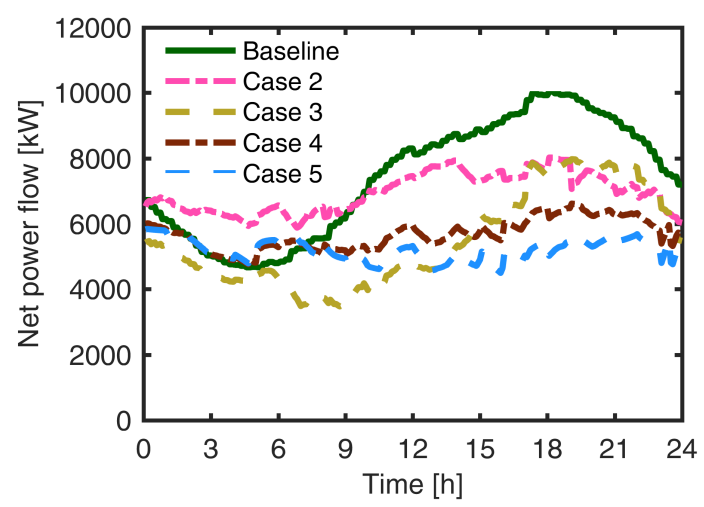

(b)

Fig. 9. Aggregated residential net power flow with HEM for the studied winter (a) and summer (b) day, respectively. The proposed HEM reduces the peak demand and alleviates the "duck curve" effect.

industrial and business sectors. Case studies based on experimental data and simulation results illustrate the decreasing trend of total power demand as the penetration of smart homes increases.

The paper also presents case studies with solar PV generation capability added to a percentage of the SET smart homes, leading to the challenging effect known as the "duck curve". In order to mitigate this issue, and benefit both the residential consumers and the utility grid, a smart HEM system is proposed to reduce the peak residential demand through the combined optimal control of the HVAC and EWH set points.

\section{ACKNOWLEDGMENT}

The support of University of Kentucky, the L. Stanley Pigman endowment, as well as the information provided by the Glasgow Electric Plant Board (EPB) are gratefully acknowledged.

\section{REFERENCES}

[1] D. Heirman, "What makes smart grid-smart—and who is in the "game"?" IEEE Electromagnetic Compatibility Magazine, vol. 1, no. 2, pp. 95-99, 2012.
[2] M. Masera, E. F. Bompard, F. Profumo, and N. Hadjsaid, "Smart (electricity) grids for smart cities: Assessing roles and societal impacts," Proceedings of the IEEE, vol. 106, no. 4, pp. 613-625, 2018.

[3] P. Denholm, M. O'Connell, G. Brinkman, and J. Jorgenson, "Overgeneration from solar energy in california. a field guide to the duck chart," National Renewable Energy Lab.(NREL), Golden, CO (United States), Tech. Rep., 2015.

[4] R. H. Schulte and F. C. Fletcher, "100conundrum," The Electricity Journal, vol. 32, no. 2, pp. $31-36,2019$.

[5] D. Watson and M. Rodgers, "Utility-scale storage providing peak power to displace on-island diesel generation," Journal of Energy Storage, vol. 22, pp. 80-87, 2019.

[6] O. Sikder and P. M. Jansson, "Thermal inertia of a building as virtual energy storage: A sustainable solution for smart grids," in 2018 53rd International Universities Power Engineering Conference (UPEC). IEEE, 2018, pp. 1-6.

[7] "TVA energyright solutions," https://www.tva.gov/file_source/TVA/Site\% 20Content/Energy/EnergyRight\%20Solutions/ERS_Highlights_2015.pdf, accessed: 2020-1-21.

[8] J. H. Yoon, R. Baldick, and A. Novoselac, "Dynamic demand response controller based on real-time retail price for residential buildings," IEEE Transactions on Smart Grid, vol. 5, no. 1, pp. 121-129, 2014.

[9] H. Gong, V. Rallabandi, D. M. Ionel, D. Colliver, S. Duerr, and C. Ababei, "Net zero energy houses with dispatchable solar pv power supported by electric water heater and battery energy storage," in 2018 IEEE Energy Conversion Congress and Exposition (ECCE). IEEE, 2018, pp. 24982503. 